\section{QIJEI}

International Journal for Educational Integrity

\title{
Editorial, Volume 7(2)
}

Welcome to the last issue of the IJEI for 2011. This issue includes the best refereed papers from the $5^{\text {th }}$ Asia Pacific Conference on Educational Integrity: Culture and Values, held at the University of Western Australia, 26-28 September 2011.

With delegates from Australia, Malaysia, Indonesia, Singapore, Hong Kong, New Zealand, Japan and India, as well as Europe and North America, the conference was a lively three days of discussion and sharing of international practice. The presentations were similarly diverse, with many focusing on what constitutes good academic integrity policy and how that policy is enacted in practice. The flavour of the conference is well represented in the five papers edited for this issue of the Journal.

Members of the 2010-2012 Australian Learning and Teaching Council (ALTC) funded project, Academic integrity standards: Aligning policy and practice in Australian universities (Tracey Bretag, Saadia Mahmud, Margaret Wallace, Ruth Walker, Colin James, Margaret Green, Julianne East, Ursula McGowan and Lee Partridge) report on an important aspect of their preliminary findings. As part of the policy analysis stage of the research, Bretag et al. identified 'five core elements' of exemplary academic integrity policy, including access, approach, responsibility, detail and support. Using a seal knot to represent the interconnected and non-hierarchical nature of the five elements, Bretag et al. make the case that an overarching commitment to academic integrity lies at the heart of an exemplary policy. The five core elements are juxtaposed with the 12 recommendations for academic integrity policy made by the Higher Education Academy (UK) to determine areas of agreement, as well as potential areas for development.

Jennifer Martin and Karen van Haeringen, from Griffith University in Queensland, describe the institutional academic integrity framework and accompanying policy document recently implemented at Griffith University. Martin and van Haeringen use a policy cycle model to analyse the process of developing and operationalising the policy. They share their experience, beginning with identifying the need for a new academic integrity policy, to developing the policy instruments, consulting with institutional stakeholders, trialling the new policy, evaluating the trial, implementing the new framework and policy across the whole institution, and finally reporting on some preliminary outcomes, including academic integrity breach decisions and student appeals. It is not surprising that Martin and van Haeringen received an ALTC Citation in 2010, "For the strategic development and implementation of institutional policy, systems and services that support a sustainable and holistic approach to promoting academic integrity among students". Nor is it surprising that Professor Anna Stewart, the Deputy Dean (Teaching and Learning) who had an instrumental role in the process, received an ALTC Citation in 2009 "For leadership in the development and implementation of a university-wide evidence-based response for the prevention and management of student academic misconduct". In addition, in 2008, the Australian Universities Quality Agency (AUQA) commended Griffith's academic integrity framework "for the adoption of an evidence-based approach to academic integrity underpinned by research literature and practice" with the result that the policy was highlighted on the AUQA Good Practice Database.

Sue Hrasky and David Kronenberg, from the University of Tasmania, also share good practice from their own institution, this time in relation to assessment design. Rather than placing responsibility for plagiarism solely with students, Hrasky and Kronenberg

The International Journal for Educational Integrity is available online at:

http://www.ojs.unisa.edu.au/journals/index.php//JEI/

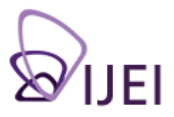


agree with international researchers that responsibility for academic integrity needs to be shared by students, staff and the institution. Using the strategies to reduce plagiarism suggested by the Centre for Study of Higher Education (CSHE) as a basis, Hrasky and Kronenberg explore the range of approaches, both educative and potentially punitive, used by teaching staff at the University of Tasmania, to address the issue of plagiarism. The authors also investigate which assessment strategies are regarded to be effective as plagiarism deterrents, and which strategies are linked to perceived impediments to curriculum design. This paper provides a solid foundation for those educators who recognise the central role they play in minimising plagiarism, and particularly those willing to redesign curriculum as part of this responsibility.

From policy and practice in Australian higher education, the fourth paper takes us to the UK, where Nadya Yakovchuk, Jo Badge and Jon Scott share the findings from a research project which aimed to explore staff and student perspectives regarding the possibility of implementing honour codes in UK universities. Although research has shown that honour codes in the American education system have the potential to reduce plagiarism, there is a paucity of empirical data to suggest that honour codes would have the same effect in other contexts. Based on data from 28 participants in six focus groups, Yakovchuk et al. conclude that although both staff and students saw the educational benefits of increased student involvement in the promotion of academic integrity policy and practice, students were less confident than staff about how this involvement might practically be implemented. In addition, the research indicated that both groups of stakeholders were resistant to the concept of an 'honour pledge', with its implied moral element. Yakovchuk, Badge and Scott have opened the door for similar research to be conducted in other contexts, and for educators to consider which aspects of American style honour codes would be most appropriate and effective in those contexts.

The final paper by Subhash Appanna and Sam Goudar in New Zealand explores the implications for academic integrity presented by broader policy developments such as those in international education. Foregrounding their discussion with a critique of the commericalisation of higher education, the authors analyse organisational responses to institutional requirements for integrity and quality in the case of a private training establishment in New Zealand. Based on a range of secondary sources coupled with personal experience, Appanna and Goudar conclude that deregulation, re-regulation, a reliance on the market as well as internal organisational controls, paves the way for possible compromises of integrity in the highly lucrative New Zealand international education industry.

The five papers from 5APCEI that make up this issue of the Journal indicate the range of research interests inherent in the field of educational integrity. At this year's conference, researchers and practitioners paid particular attention to the intersection of policy and practice. The ongoing findings and output from the ALTC Academic Integrity Standards Project has the potential to highlight both the gaps between policy and practice and how the two may be more meaningfully aligned, not only in the Australian context, but in the international arena. Interested researchers are encouraged to find out more about the project via the website: http://www.apfei.edu.au/altc-priorityproject.html.

I hope you enjoy this issue featuring the best papers from 5APCEI. I would like to take this opportunity to thank all of the presenters (and of course the organising committee, reviewers and delegates) for making possible such a stimulating and productive conference.

Tracey Bretag

Editor, International Journal for Educational Integrity

December 2011 